\title{
A EXPRESSIVIDADE DA DANÇA CIRCULAR BUSCA HOSPITALIDADE, ACOLHIMENTO E AMOROSIDADE NAS RELAÇÕES
}

\section{THE EXPRESSIVENESS OF THE CIRCULAR DANCE SEEKS HOSPITALITY, WELCOMING AND LOVING RELATIONSHIPS}

\section{LA EXPRESIVIDAD DE LA DANZA CIRCULAR BUSCA HOSPITALIDAD, ACOGIDA Y AMOROSIDAD EN LAS RELACIONES}

\author{
Newton Ávila ${ }^{1}$ \\ Maria Luiza Cardinale Baptista ${ }^{2}$
}

\begin{abstract}
RESUMO
Esta pesquisa propõe a dança circular, como expressão de vínculos de acolhimento e amorosidade, em condições de oferecer sinalizadores para a hospitalidade. Tem como objetivos específicos: apresentar a dança circular num contexto relacional entre os sujeitos; relacionar os conceitos de acolhimento e amorosidade à dança circular; identificar sinalizadores de hospitalidade, nos vínculos marcados pelo acolhimento e amorosidade, em decorrência da dança circular. A Cartografia de Saberes, proposta por Baptista, é a orientação metodológica para a produção deste estudo, com realização das trilhas de saberes pessoais, saberes teóricos e a usina de produção. Foram realizadas aproximações investigativas, com levantamento bibliográfico, desenvolvimento de intervenções de dança em diversos ambientes e observação do corpo participante. Nas ações práticas, observação direta, observação participante, rodas de conversa, relatos de vivências e experimentação com desenvolvimento da dança circular. Os resultados indicaram que o desenvolvimento da dança circular, proporcionou, aos sujeitos participantes, sensação de bem-estar, laços de proximidade, acolhimento e amorosidade. Concluiu-se que a dança circular é uma forma de integrar o corpo e sua expressividade, em situação de comunicação e expressão. É capaz de acionar o pensamento e explorar a criatividade, estabelecendo troca com o 'outro'. Proporciona sensação de pertencimento e provoca soltura nos corpos, relaxamento e relação-convívio.
\end{abstract}

Palavras-chave: Hospitalidade; Dança circular; Acolhimento; Amorosidade.

\begin{abstract}
This research proposes the circular dance, as an expression of the bonds of acceptance and amorousness, in conditions to offer signs for the hospitality. It has specific objectives: to present the circular dance in a relational context between the subjects; to relate the concepts of welcoming and amorous to circular dance; to identify flags of hospitality, in the bonds marked by the reception and amorousness, as a result of the circular dance. The Cartography of Saberes, proposed by Baptista, is the methodological orientation for the production of this study, with the realization of the tracks of personal knowledge, theoretical knowledge and the production plant. Investigative approaches were carried out, with a bibliographical survey,

\footnotetext{
${ }^{1}$ Graduação em Comunicação, habilitação Relações Públicas. Especialização em Gestão de Pessoas. Mestrado em Turismo e Hospitalidade. Instituição/Afiliação: Universidade de Caxias do Sul, UCS. E-mail: newtonavila@ hotmail.com

2 Doutora em Ciências da Comunicação, pela ECA/USP. Professora e pesquisadora do Programa de Pós-Graduação em Turismo e Hospitalidade da UCS (BRASIL). Pós-doutoranda e Professora colaboradora do Programa de Pós-Graduação em Sociedade e Cultura da Amazônia (PPGSCA-UFAM). Instituição/Afiliação: Universidade de Caxias do Sul, UCS. E-mail: mlcbaptista@ucs.br
} 
development of dance interventions in several environments and observation of the participant body. In practical actions, direct observation, participant observation, talk wheels, experiences reports and experimentation with circular dance development. The results indicated that the development of the circular dance provided the participants with a feeling of well-being, close ties, acceptance and love. I conclude that circular dance is a way of integrating the body and its expressiveness, in a situation of communication and expression. It is capable of triggering thought and exploring creativity, establishing exchange with the 'other'. It provides a sense of belonging and causes ease in bodies, relaxation and relationship.

Keywords: Hospitality; Circular dance; Welcoming; Amorosity.

\section{RESUMEN}

Esta investigación propone la danza circular, como expresión de vínculos de acogida y amorosidad, en condiciones de ofrecer señalizadores para la hospitalidad. Tiene como objetivos específicos: presentar la danza circular en un contexto relacional entre los sujetos; relacionar los conceptos de acogida y amorosidad a la danza circular; identificar indicadores de hospitalidad, en los vínculos marcados por la acogida y amorosidad, como consecuencia de la danza circular. La Cartografía de Saberes, propuesta por Baptista, es la orientación metodológica para la producción de este estudio, con realización de los senderos de saberes personales, saberes teóricos y la usina de producción. Se realizaron aproximaciones investigativas, con levantamiento bibliográfico, desarrollo de intervenciones de danza en diversos ambientes y observación del cuerpo participante. En las acciones prácticas, observación directa, observación participante, ruedas de conversación, relatos de vivencias y experimentación con desarrollo de la danza circular. Los resultados indicaron que el desarrollo de la danza circular, proporcionó a los sujetos participantes, sensación de bienestar, lazos de proximidad, acogida y amorosidad. Concluiu-se que la danza circular es una forma de integrar el cuerpo y su expresividad, en situación de comunicación y expresión. Es capaz de accionar el pensamiento y explorar la creatividad, estableciendo intercambio con el otro. Proporciona sensación de pertenencia y provoca soltura en los cuerpos, relajación y relación-convivencia.

Palabras clave: Hospitalidad; Danza circular; Acogida; Amorosa.

\section{INTRODUÇÃO}

O presente artigo é parte da dissertação de Mestrado intitulada "Dança Circular e Hospitalidade: um corpo que se expressa e acolhe com amorosidade", e, que foi defendida em 2017, no Programa PPGTURH - Turismo e Hospitalidade, da Universidade de Caxias do Sul, UCS, sob a orientação da $\operatorname{Prof}^{a}$. Dra ${ }^{a}$. Maria Luiza Cardinale Baptista e coorientação da Prof ${ }^{a}$. Dr ${ }^{\mathrm{a}}$. Susana de Araújo Gastal. 
Este trabalho propõe apresentar a dança circular como expressão ${ }^{3}$ de vínculos de acolhimento e amorosidade, em condições de oferecer sinalizadores para a hospitalidade. A proposta em estudar esta problemática vem da observação empírica das ações e reações dos sujeitos em suas relações, pressupondo a necessidade de produzir uma convivência baseada na hospitalidade, que crie vínculos de acolhimento $\mathrm{e}$ amorosidade entre as pessoas. Especificamente, objetiva: apresentar a dança circular num contexto relacional entre os sujeitos; relacionar os conceitos de acolhimento e amorosidade à dança circular; identificar sinalizadores de hospitalidade, nos vínculos marcados pelo acolhimento e amorosidade, em decorrência da dança circular.

A dança analisada neste estudo é a dança circular. Esta se apresenta como algo que pulsa, traz movimento, propõe expressividade e faz refletir (a possível constituição de relação consigo mesmo e com o 'outro'4 ${ }^{,}$. A dança, pode-se dizer, teve um papel preponderante ao longo da história da humanidade, uma vez que, desde a Antiguidade até a contemporaneidade, percebe-se a necessidade contínua em interagir e comunicar-se por meio dela.

Os pressupostos metodológicos deste trabalho têm como base a Cartografia de Saberes (BAPTISTA, 2014). A Cartografia de Saberes, resumidamente, trata-se de abordagem transdisciplinar, alinhada aos pressupostos teóricos da Ciência Contemporânea, na perspectiva complexo-sistêmica, sendo possível perceber sua potência para criar uma sistematização, sem aprisionamento, de acordo com Baptista (2014). Por meio de seu processo, compreendem-se os critérios que orientam o cartógrafo, tomando como base o conceito de cartografia, apresentado por Sueli Rolnik (1989), segundo o qual Baptista (2014) afirma que existe uma 'trama de trilhas' a serem acionadas. A estratégia metodológica consistiu em realizar 'trilhas' com a produção de saberes pessoais, saberes teóricos e usina de produção, o que permitiu deixar fluir

\footnotetext{
${ }^{3} \mathrm{O}$ termo 'expressão' utilizado no objeto de estudo vincula-se a diversos tipos de linguagem. Vale ressaltar que linguagem, no mundo contemporâneo, perpassa atividades individuais e coletivas. Verbais ou não verbais, as linguagens se cruzam, se completam e se modificam incessantemente, acompanhando o movimento de transformação do ser humano e suas formas de organização social (FOUCAULT, 2004). A dança, como forma expressiva, congrega elementos de linguagem.

4 'Outro' neste estudo refere-se à relação que pode ser construída ao buscar a percepção do olhar do outro, utilizando-se do pensamento de Levinas (1988). O autor diz que ao aceitar o outro nos tornamos responsáveis por esse outro, sem esperar nada em troca, apenas um desejo gratuito que provoca um movimento ao outro, um desejo de conhecer absolutamente o outro, resgatando a si mesmo e recuperando a alteridade do outro. Assim, ao pensar em relações humanas é possível perceber que aquele que chega na predisposição do encontro é um outro em relação a mim (um estranho, um desconhecido). À vista disso, os olhos dos outros serão os espelhos dos nossos atos. Ressalto também, que o uso das aspas posta na palavra outro tem o efeito de enfatizar a escrita sobre essa relação.
} 
amarrações da pesquisa de cunho exploratório. As perspectivas metodológicas foram realizadas com aproximações investigativas, que ocorreram com levantamento bibliográfico, desenvolvimento de intervenções de dança em diversos ambientes e observação do corpo participante (na expressividade e na comunicação). Nas ações práticas, observação direta, observação participante, rodas de conversa, relatos de vivências e experimentação com dança circular.

Segundo Gil (1999), a observação constitui elemento fundamental para a pesquisa, é, também, a utilização dos sentidos humanos, para obter determinada informação sobre aspectos da realidade. Corroborando com esta afirmação, Rúdio (2002) acentua que o termo observação não se trata apenas de ver, mas, de averiguar, sendo por este meio, mais fácil de conhecer as pessoas, os acontecimentos e os fenômenos. Assim, a observação direta e a observação participante, convergem com a possibilidade de tonificar as relações.

A respeito das rodas de conversa, é um meio para uma comunicação dinâmica e produtiva, com estímulo ao diálogo, assim como um dispositivo para ser utilizado como prática metodológica de aproximação entre os sujeitos. É também, um espaço de partilha e confronto de ideias, proporcionando a liberdade da fala e da expressão, em que se propõe a construção do conhecimento coletivo, possibilitando a transformação (FREIRE, 1991). Para elucidar, trago um exemplo do Amorcomtur! Grupo de Estudos em Comunicação, Turismo, Amorosidade e Autopoiese, que vem desempenhando práticas experienciadas pelas rodas de conversa, e do qual faço parte, constatando que se trata de um dispositivo libertador e extremamente desafiante para a vinculação das pessoas. E em relação à vivência, etimologicamente deriva do grego viventia, que significa 'o fato de ter vida'. A vivência como elemento constitutivo de vida, de experiência, segundo Merleau-Ponty (1994), mostra a expressividade como extensão do entendimento do corpo, em que se permite, através dela, experienciar, perceber e refletir, e contido em toda a dimensão humana, constitui como um "veículo do ser no mundo" para explorar novas possibilidades.

Justifica-se a importância da relação da dança com a hospitalidade, acolhimento e amorosidade, trazendo referenciais teóricos para a construção deste estudo. Neste contexto, falar de hospitalidade é entender a fruição que habita na relação com o lugar e na relação com o 'outro', implicando a relação humana. Por lugar de hospitalidade, pode-se entender aquele que é aberto ao outro, que possibilita o sentir-se à vontade, o ter pertencimento e o bem-estar ao 
estar no ambiente (BAPTISTA, 2008). Dessa forma, é possível que o espaço possa se transformar em lugar, num movimento consciente de humanização desse espaço. E pode fazer com que os sujeitos, ao se sentirem bem, tenham reações de comportamento favoráveis ao encontro, tornando possível a construção das relações de convivência, observados neste estudo, por meio da dança.

Finalmente, a amorosidade, pode-se dizer, garante amor e acolhimento, para tornar as relações mais agradáveis. Assim, a amorosidade é libertária. Ela é uma atitude que começa na mente e acaba se instalando no coração, como um jeito novo de ser, e só acontece em quem é capaz de amar. Para isso, é necessário, viver o amor em si. Deixar despertar em seu interior a plenitude do amor. Sem rótulos. Sem pré-conceitos. Sem distinções. A ação da amorosidade, também permite que se aproximem as pessoas do conjunto de virtudes, pois, nela, estão incluídos o cuidado ${ }^{5}$, o respeito ${ }^{6}$, a confiança. Vem ao encontro dessas afirmações o que Maturana (1998) apresenta, pontuando que as emoções não são algo que obscurece o entendimento, não são restrições da razão: as emoções são dinâmicas corporais que especificam os domínios de ação em que nos movemos. Evidencia o autor ser possível perceber que as emoções fazem parte do cotidiano dos sujeitos. Considera-se que a dança circular produz e se alimenta da amorosidade. A dança traz consigo o tato, o contato com o toque das mãos, que possibilita a sensação de odor e temperatura, as tensões nervosas, bem como revela sentimentos no reconhecimento do 'outro', na aproximação.

Essas constatações permeiam a dança circular, que pressupõe a relação 'eu' e o ‘outro', por meio do círculo e do auxílio mútuo entre os sujeitos. Considera-se que a primeira formação desenvolvida na vida social e em grupo, foi a roda. Com isso, foi percebido pelas culturas antigas que, especialmente a forma circular, era o estímulo para estar e fazer junto com o 'outro'. O círculo tem, em sua consistência, a forma geométrica espacial, que simboliza a perfeição e harmoniza, com a plenitude que o ser humano está sempre em busca para atingir, pois a centralidade circular põe todos de frente em sintonia (COSTA, 1998). E o mais

\footnotetext{
5 "O cuidado que aquele que acolhe dá à preparação e ao embelezamento do espaço do acolhimento é tão significativo quanto a qualidade da relação que se estabelece no momento do acolhimento" (AVENA, 2008, p. 421-422).

6 "Respeito do homem consigo mesmo, do homem com o próximo e deste com a Sociedade que o cerca e, fundamentalmente, do homem com o meio ambiente, ou seja, com tudo ao seu redor" (BOCCHETTI, 2007 apud AVENA, 2008, p. 67).
} 
impressionante do círculo, é a cooperação que pode existir entre os que estão na roda, se ajudando mutuamente, simplesmente por fazer a roda se movimentar harmonicamente.

Na constituição do círculo, há uma conduta inclusiva, não importando as diferenças de classe social, etnia, gênero, faixa etária. O círculo e a roda comparam-se a um sistema orgânico, no qual “[...] as pessoas são vistas como células, individualmente criativas [...]” (RAMOS, 1998, p. 175). E em momentos de descontração ritmos, danças, mistura de culturas e até mesmo cantos, são somados para se fazer perceber a importância que tem cada um na roda.

\section{PASSOS METODOLÓGICOS E EXPRESSIVIDADE POR MEIO DA DANÇA}

A metodologia é o estudo dos caminhos para se chegar a um determinado fim. Definir a metodologia é sempre um desafio, pois ela dá corpo ao trabalho e presentifica a consistência do objeto estudado. Assim, dentre as possibilidades metodológicas, busquei a que, a meu ver, se fez mais condizente com o propósito do meu estudo, numa possibilidade de romper com a tradição que limita a inventividade e a criação do pesquisador. E, eis que cheguei, então, à estratégia metodológica da Cartografia de Saberes, proposta por Baptista (2014).

A cartografia apresenta-se como um dispositivo científico de investigação, buscando dar conta da complexidade do processo e tornar possível a construção do conhecimento, com suas amplitudes e intensidades. Propõe a interpretação e a reinterpretação dos significados, considerando novas formas de compreensão, capazes de dar conta de ambientes sociais de grande complexidade. E, neste estudo, aplica-se ao convívio, à interação social e às relações. Nesse sentido, a proposição se alinha ao pensamento de Morin (2004) ao trazer que o conhecimento é sempre uma tradução, seguida de uma reconstrução. $O$ autor expõe que, mesmo no fenômeno da percepção em que os olhos recebem estímulos luminosos que são transformados, decodificados, transportados a um outro código, e esse código binário transita pelo nervo ótico, atravessa várias partes do cérebro e isto é transformado em percepção, logo a percepção é uma reconstrução. Morin (2012) pontua, também, que “[...] podemos dizer até que o conhecimento progride não tanto por sofisticação, formalização e abstração, mas, principalmente, pela capacidade de contextualizar e englobar [...]” (p. 14). Cartografar é construir mapas a partir da capacidade de percepção do pesquisador, segundo Baptista (2014) com base em Rolnik (1989). Trata-se de uma espécie de mapeamento que, neste caso, acompanha e é feito enquanto certos mundos desintegram-se, perdem seu significado, e outros 
se formam. Mundos que são criados para expressar afetos contemporâneos, em relação ao qual universos existentes se tornam obsoletos. O cartógrafo tem a tarefa de dar voz aos sentimentos que pedem passagens (ROLNIK, 1989). Baptista (2014) explica que se cria uma composição, que "[...] implica em mergulho no objeto/fenômeno escolhido para estudar e no conhecimento já produzido a respeito, por outros investigadores, bem como no reconhecimento e a efetivação, possíveis com a vivência da pesquisa [...]" (p. 344).

Baptista (2014) ainda complementa que o cenário da ciência transdisciplinar caosmótica exige outro tipo de pesquisa, em termos de operacionalização. E propõe que o trabalho da pesquisa deve ser iniciado em várias frentes, em várias trilhas investigativas. Por fim, expõe que o processo de investigação é “[...] o de investimento desejante, na busca de conhecimento. Trata-se de uma viagem investigativa em que o pesquisador se reinventa, se renova, se re-faz [...]” (BAPTISTA, 2014, p. 350). A recomendação do uso da Cartografia de Saberes para construir a 'trilha' se sobressai para a pesquisa qualitativa, mesmo que se utilizem métodos e técnicas quantitativas. "Está presente, na proposição, a associação entre a investigação e a metáfora de viagem intelectual, o que justifica a palavra 'trilha', na expressão 'trama de trilhas'[...]" (BAPTISTA, 2014, p. 344). Assim, começa a se delinear, desde essa palavra, a ideia de esboçar um 'desenho' de uma estratégia metodológica, com possibilidades de acionamento de dados pelo investigador, ao longo da pesquisa.

Assim, utilizando-se da estratégia metodológica Cartografia de Saberes, proposta por Baptista (2014), ao buscar a realização de aproximações investigativas (levantamento bibliográfico, desenvolvimento de dança circular), estas aconteceram em diversos ambientes e em várias cidades, do Rio Grande do Sul ao Paraná (Vinícola Peterlongo, Garibaldi/RS; Centro de Convivência do Idoso São José, Farroupilha/RS; Centro Municipal de Cultura Henrique Ordovás Filho, Caxias do Sul/RS; Brique da redenção, Porto Alegre/RS; Feira de Arte e Artesanato do Largo da Ordem, Curitiba/PR). Tiveram como música de fundo 'Zorba - Sirtaki Originale', seguida de explicativos sobre a dança circular e o propósito da atividade, bem como, a demonstração dos passos de Dança Circular Grega.

Já as ações investigativas (observação direta, observação participante, rodas de conversa, relatos de vivências e experimentação com a dança), se deram no objeto de estudo de campo, definido em concordância com minha orientadora, pelo Sesc-RS, que apresenta, desde 1946, uma sólida trajetória em Turismo Social, elencando educação, cultura, recreação, lazer, 
assistência e saúde. Ali foram executadas cinco ações, distribuídas em cinco cidades do Rio Grande do Sul, no período compreendido entre julho e agosto de 2017, tendo como maior público, os grupos da Maturidade Ativa ${ }^{7}$. Dentre as cidades estão: Nova Roma do Sul, Caxias do Sul, Bento Gonçalves, Vacaria e Farroupilha. E a música escolhida para conduzir os passos das danças (Dança Circular Sagrada, Dança Circular Celta, Dança Circular Grega), foi 'Me and My Cello (Happy Together) - The Piano Guys'. Relato também que, foi pedido permissão para gravar as falas, utilizadas neste estudo, e, depois, filtrar as respostas para transcrever os relatos das vivências que contaram com a expressividade e o diálogo espontâneo dos participantes. Houve também, um Termo de Adesão Voluntariado atestado pelo Sesc-RS, em que foi permitido executar as danças circulares nas dependências da empresa.

Por conseguinte, Baptista (2014) apresenta as trilhas para a proposição da Cartografia de Saberes, na prática da pesquisa.

A primeira trilha proposta é a que se refere aos 'saberes pessoais'. Nela, é importante o investigador refletir o que sabe sobre determinado assunto. Com isso, irá se autorizar a escrever textos sobre as temáticas envolvidas nesse objeto de estudo. Assim, relaxando e expondo a escrita sobre o que pensa, irá liberar os pensamentos, fazendo uma sondagem de si, dando direcionamento do seu assunto. Emerge, aqui, portanto, o diário de campo, como fundamental lição de resgate dos saberes pessoais.

A segunda trilha a ser cartografada são os saberes teóricos. Com as temáticas escolhidas, o pesquisador deverá percorrer as trilhas desses conhecimentos. Neste momento, a autora propõe que se "[...] monte um quadro com os assuntos e as referências teóricas encontradas sobre cada um deles. Esse quadro é importante, porque ajuda a visualizar a cartografia teórica e suas linhas investigativas [...]" (BAPTISTA, 2014, p. 351). Defende, também, que cada subtemática expressa em palavras-chave tenha referências bibliográficas, mostrando a direção do trabalho teórico.

A terceira trilha, chamada pela autora de laboratório de pesquisa ou usina de produção, propõe o envolvimento do investigador para criar situações que deem vida à pesquisa. E fundamenta que se faz necessário ir a campo, já nas aproximações, para sentir e

\footnotetext{
${ }^{7}$ O Sesc Maturidade Ativa, criado em 2003, tem como objetivo promover a qualidade de vida e o envelhecimento ativo de pessoas com idades a partir de 60 anos. No programa, os participantes reúnem-se para conviver, divertir, confraternizar, aprender, desenvolver seus potenciais, além de realizar trabalhos comunitários e solidários (SESC, 2017).
} 
saber das reais escolhas, decisões, que afloram do próprio campo de pesquisa, tendo, por este fim, a segurança do caminho com o foco alinhado aos objetivos. A autora também chama a atenção no que diz respeito às diversas estruturas da pesquisa, de níveis mais profundos, em que emergem, muitas vezes, 'pensamentos picados'. Expõe que o conhecimento e a pesquisa não se produzem “[...] apenas na consciência, nas instâncias do pensamento racional. Quando alguém investiga, esse sujeito investe-se em direção ao objeto paixão-pesquisa e isso significa que o sujeito todo pesquisa e vibra com a investig[ação]" (BAPTISTA, 2014, p. 352). E, por fim, ainda atenta aos processos “[...] caosmóticos também internos, o pesquisador deve estar sempre pronto a registrar essas brotações autônomas, para, com elas, em grande parte das vezes, puxar fios que ajudam a desenvolver as trilhas de saberes [...]” (Ibid., p. 352), numa formulação necessária para a proposição do estudo.

Tem-se, com isso, que o papel do pesquisador é central, sendo que é a partir das percepções, das sensações e das afetividades vivenciadas que se constroem conhecimentos. Neste sentido, o método cartográfico “[...] desencadeia um processo de desterritorialização no campo da ciência, para inaugurar uma nova forma de produzir o conhecimento, um modo que envolve a criação, a arte, a implicação do autor, artista, pesquisador, cartógrafo [...]”" (MAIRESSE, 2003, p. 259 apud ROMAGNOLI, 2009, p. 170). Isso possibilita a criação na constante relação do pesquisador com o seu objeto, construindo um outro olhar para o conhecimento com a experimentação, os relatos e o diálogo. Assim sendo, o cartógrafo, na possibilidade de abarcar a complexidade, coloca os problemas e investiga o global, concebendo no campo de pesquisa um outro olhar. Ele absorve matérias de expressão de qualquer procedência, para compor suas cartografias, já que: "Todas as entradas são boas, desde que as saídas sejam múltiplas [...]" (ROLNIK, 1989, p.66).

Neste contexto, as ações investigativas geraram relatos e, por meio destes, foram criados quadros sínteses, buscando observar as propriedades do campo, dialogando com as falas dos participantes, elencando a hospitalidade, o acolhimento e a amorosidade. Também foi possível observar palavras-chave identificadas nas manifestações orais, tendo como base a fundamentação teórica deste estudo. Foram palavras-chave identificadas na Hospitalidade: Receber e ser recebido; Abertura para a relação com o outro; Trocas; Bem-estar no ambiente; Sentir-se bem; Relações de convivência; Aceitação do outro; Pertencimento. Foram palavraschave identificadas no Acolhimento: Reconhecimento do outro na convivência; Envolvimento; 
Entrelaçamento; Permitir o contato e a intimidade; Cuidar do outro; Empatia; Atitude de disponibilidade interna para o encontro; Se reconhecer, interagir e se hospedar mutuamente; Laços de proximidade. Foram palavras-chave identificadas na Amorosidade: Amor em sentido pleno; Afetividade; Emoções; Sentimentos; Aceitação mútua em relação ao outro na convivência.

Assim, é possível dizer que, houve uma entrega completa do sujeito, com seu corpo e sua expressividade, na composição da roda, na arte do encontro proporcionada pela dança circular. Permitindo, assim, que o amor, como uma emoção fundamental, possibilite a representação do reconhecimento e da aceitação. Transformando o 'outro' e redescobrindo a dinâmica das relações. Fazendo refletir, aprender e se modificar.

\section{A ARTE DO ENCONTRO NA DANÇA CIRCULAR}

A dança circular, reforçando a afirmação já dita, se apresenta como algo que pulsa, traz movimento, propõe expressividade e faz refletir (a relação consigo mesmo e a relação com o 'outro'), não somente em sua execução corpórea, mas em sua vivência que estabelece contato com tato. Posto isso, proponho trazer um breve resgate da composição da roda, um histórico com a origem e as manifestações dos formatos de danças circulares.

\subsection{Composição da roda}

A primeira formação social e em grupo seria a roda (COSTA, 1998). Assim, como já trazido, é possível dizer que o círculo, em sua arquitetura, simboliza harmoniza, a plenitude que o ser humano busca atingir. A centralidade circular põe todos frente a frente, em sintonia (COSTA, 1998). Em descontração nele são somados ritmos, cantos, movimentos corporais e, até diferenças culturais, sem anular as individualidades.

As danças circulares, são polissêmicas, despertando linguagens e diferentes saberes que estendem o repertório artístico-cultural. Desta forma, a aproximação estabelecida na roda possibilita o autoconhecimento ao fazer com que cada um se perceba e perceba o 'outro'.

Nesse sentido, Camargo (2015) acrescenta que dançar juntos em roda é compartilhar bens comuns e celebrar a vida em todos os seus sentidos e dimensões. A autora também afirma que, para ser aproveitada ao máximo a experiência de dançar em roda, é preciso que os sujeitos se permitam dançar uns com os outros de mãos dadas (ou não), na roda, vivenciando a 
influência simbólica do círculo. E complementa, dizendo que, em meio a pessoas semelhantes e dissemelhantes, diferentes em pensamentos e ações, mas unidas na busca de aprender umas com as outras, os sujeitos trocam experiências no cotidiano da roda. Isso permite interagir e cooperar com o grupo, “[...] respeitando as diferenças de ritmos corporais, as características e estilos individuais e aprendendo a ocupar os espaços sem desrespeitar as fronteiras necessárias que nos garantem o direito de serem, todos, 'humanos'[...]” (CAMARGO, 2015, p. 66). Ainda segundo a autora, a roda das danças circulares torna-se representativa de uma mandala humana.

\subsection{Um pouco de história da dança circular}

A dança circular ou dança de roda é uma riqueza cultural, das mais antigas do Ocidente. Sua origem estaria na Antiguidade, em pequenos povoados ou aldeias, mas poderia ser ainda mais antiga se vista como atrativa ao humano. Expressa-se, desse modo, como sinônimo de vida espontânea e integrante do dia a dia (WOSIEN, 2000). A prática das danças circulares, era comum a muitas civilizações antigas, para celebrar a chegada da chuva, das estações do ano, do movimento do Sol, o agradecimento aos deuses, entre outros (COSTA, 1998). Até os primeiros séculos da era cristã estava inserida nas práticas religiosas e na vida em comunidade. Também era possível perceber, que “[...] em tempos remotos, por meio da dança, o homem identificava-se com os ritmos da natureza. Reconhecia e imitava os movimentos e as forças nela presentes [...]" (OSTETTO, 2006, p. 69).

As danças circulares expressavam uma sabedoria que, resistiu às mudanças de linguagem, localização, religião e nacionalidade por milhares de anos, e que ainda são consideradas como primeiras manifestações da criatividade coletiva (COUTO, 2008).

A partir da Idade Média, desvincula-se da Igreja e exibe outros contornos, apresentando gêneros, como o ballet. Passa a adquirir um caráter festivo, sendo representada em festejos populares e praças públicas (FARO, 2011). Atravessa a Renascença com os descobrimentos nas belas artes e, além das danças de roda, passa a exibir ritmos como polcas e mazurcas. Na Modernidade, mesmo se modificando, a roda continua representando, na experiência do dançar com o movimento, a interação entre os corpos na dança circular. Por conseguinte, a dança circular ou dança de roda, com o passar dos tempos, parece ter sido a matriz de muitas outras danças, ao apresentar relação com o contexto ritualizado em conexão com a integração humana. Rememoram povos, tradições e culturas, ritos e símbolos (WOSIEN, 
2000). E no compartilhar dos gestos de mãos dadas atrelados à música, dando forma a roda, floresce a expressividade corporal.

\subsection{Formatos da dança circular}

As danças circulares recebem denominações. Adquirem o nome de Danças Circulares Sagradas a partir do interesse do pesquisador de danças folclóricas e étnicas, coreógrafo e bailarino alemão Bernhard Wosien, por uma prática corporal diferenciada para expressar os sentimentos (RAMOS, 1998). Wosien ensinou, pela primeira vez, um grande repertório de danças folclóricas, no norte da Escócia, na década de 1970, quando fez uma visita a Comunidade de Findhorn. A Dança Circular se torna "Sagrada", pelo fato de permitir que os participantes entrem em contato com sua essência, com seu eu. No momento deste contato, tem-se a união do corpo (matéria) com o espírito (energia). Acredita-se que, ao dar as mãos em círculo, cria-se um fluxo de energia que vai sustentar o campo que se forma com a presença das pessoas e com todos os elementos da natureza presentes no ambiente (WOSIEN, 2000). As danças possuem passos que vão dos mais simples aos mais elaborados, e podem se utilizar de músicas étnicas, clássicas e new age. Desta forma, pode-se dizer que, de 1976 em diante, este movimento se espalhou pelo mundo.

A classificação Dança Circular Celta, reporta ao século XII, na Irlanda, em que começaram a ser apresentadas em castelos, para a realeza no século XVI (POWELL, 1965). Na tradição celta, dançava-se em rituais em honra ao Sol e ao carvalho buscando conectar-se com a sabedoria universal. Segundo Powell (1965), os celtas eram conhecidos por apreciarem a música, a poesia e a dança, com alegria e soltura em seus movimentos, recorrentes nos períodos de celebrações religiosas, em casamentos ou nas celebrações de vitórias militares.

Outro formato de dança circular apresentada é a Dança Circular Grega, trazendo, da Grécia Antiga, o costume de dançar, com as mãos dadas. As pessoas, ao fazerem oferendas e homenagearem aos deuses, dançavam em volta de árvores ou fogueiras. As Danças Circulares Gregas, muito semelhantes às Danças Circulares Sagradas, pressupõe caminho para o encontrar a si mesmo, permeando o encontrar-se com a comunidade (WOSIEN, 2000). Nessa dança, pelas amarrações circulares exprimem-se movimentação, sensações, sentimentos e emoções, podendo constituir vínculos e relações. A dança é uma das formas de expressão que melhor representam o espírito grego e também a história da Grécia, seus martírios, suas conquistas e 
festas, seu dia a dia, suas imensas alegrias e profundas tristezas. Os gregos antigos consideravam a dança essencial para a educação, para o culto e para o teatro. E também acreditavam que era um presente dos Deuses para o sujeito esquecer, através dela, suas dores e tristezas da vida.

As danças circulares ganham ainda, denominações como dança dos povos (muitas com origem no folclore de cada país, outras tradicionais de comemorações, colheitas, retratadas em manifestações populares e inicialmente em âmbito familiar); danças meditativas (através do movimento repetido, pode-se entrar em estado de meditação, os ritmos musicais mais usados são de músicas clássicas, tradicionais e new age); danças de natureza e de plantas curativas (coreografias que reverenciam a natureza e outras que vibram a energia das plantas curativas); danças contemporâneas (coreografadas por dançarinos da atualidade, algumas para músicas tradicionais, outras para músicas contemporâneas, com base nos passos e nos movimentos de cada tradição, tais como as danças alemãs, italianas, portuguesas tradicionais coreografadas para shows e festas típicas) (RAMOS, 1998). Dessa forma, contam histórias e trazem significados variados de acordo com suas origens. Também é possível perceber que existem danças de variados povos, como as tradições culturais dos ciganos, a alegria e os passos saltitantes dos gregos, os rituais religiosos dos povos indianos, as manifestações indígenas, africanas, israelitas, brasileiras e celtas (OSTETTO, 2006).

\section{CÍRCULO DE REFLEXõeS SOBRE AS RELAÇÕES NA DANÇA}

A prática da dança circular permite notar que cada ato de dançar é uma nova descoberta e provoca reações diferentes nas pessoas. Assim, ao analisar, neste estudo, alguns grupos por determinado tempo, foi possível verificar que essas práticas trouxeram ao público participante que, a comunicação pelo corpo por meio da dança, é capaz de influenciar as relações, o corpo é gerador de comunicação a todo instante e sua expressividade corporal delimita os anseios e as atitudes frente ao desconhecido. Também é perceptível que esse corpo, através da linguagem verbal e corporal, exprime emoções e sentimentos, possuindo uma função de conhecimento (de si e do 'outro') e de expressão. Neste contexto, o conjunto das reflexões que se trouxe, entre atitudes, conceitos e novas maneiras de pensar as relações, permitiu refletir sobre a questão deste estudo: a dança circular como expressão de vínculos de acolhimento e amorosidade, em condições de oferecer sinalizadores para a hospitalidade. Na reflexão 
filosófica acerca das relações, reside a parcela de contribuição desta pesquisa para o campo da hospitalidade.

A reflexão sobre a hospitalidade, é de importância no que tange ao relacionar-se com o ‘outro', indo além da interação, perfazendo o caminho da construção do convívio, para, com o acolhimento e a amorosidade, efetivar as relações. Perazzolo, Santos e Pereira (2013) contribuem trazendo que a hospitalidade é um fenômeno que se instala no espaço constituído entre o sujeito (na sua forma singular e coletiva) que deseja acolher e o sujeito que deseja ser acolhido. E mais, pontuam que, no espaço em que o acolhedor se transforma em acolhido e o acolhido em acolhedor, há um movimento alternado e necessário para que a hospitalidade ocorra. Na mesma linha de considerações, Camargo (2015) defende, que a hospitalidade, passa pela intimidade do calor humano e pode ser compreendida como uma relação em que se estabelece uma troca (entre receber e ser recebido), pensamento este, também corroborado em Baptista (2005).

A hospitalidade, na conexão com a dança e as relações, possibilita responder os tópicos enunciados nos questionamentos da pesquisa. São perguntas a serem respondidas: Como se estabelecem as relações na dança? O que elas provocam nos sujeitos que dançam? Como relacionar os conceitos de acolhimento e amorosidade à dança circular? O que pode ser considerado nessas relações, para oferecer sinalizadores para a hospitalidade?

A dança, assim como todas as artes, constituiu-se na necessidade de expressão humana. Em sítios arqueológicos é possível ver pinturas rupestres representando rodas de dança, constatando que as rodas em círculo são uma das formas mais antigas de celebração comunitária (COSTA, 1998). As danças circulares trazem a disponibilidade de cada pessoa em estar na roda, dançando, se ajudando mutuamente e incentivando cada participante a se expressar no que têm de melhor, sem enfatizar a técnica em si, mas a troca relacional que o círculo oferece (RAMOS, 1998). Corroborando com essas afirmações, trago o relato de uma participante na segunda ação investigativa, quando disse que: "Ninguém aqui queria fazer melhor. Queria fazer junto".

A dança traz o convívio, possibilita perceber o outro, aprender com ele e reaprender a si mesmo. Conforme Jayme; Fausto, 2011 apud Reis; Tibeau; Mutarelli; Neto, 2017, p. 4), ela "convida a entrar em contato com o outro e suas diferenças", assim como, faz refletir sobre a capacidade de conviver junto de pessoas desconhecidas. Assim, as relações na dança e o que 
elas provocam nos sujeitos que dançam, se estabelecem de maneira espontânea, gratuita, em que os participantes, imbuídos de prazer pelo envolvimento da dança, se soltam, deixando a energia fluir e pulsar em seus corpos. Nas palavras de Camargo (2015), o que acontece na roda, além de não haver hierarquia, é que os participantes perfazem uma troca de conhecimentos, de cumplicidade, de generosidade, de gentileza, de harmonia, de humanidade e de outras qualidades humanas que cada um tem a oferecer. Do mesmo modo, exemplifica a autora, que não há um número exato de pessoas a participar na roda, o fundamental é o desejo de estar inteiramente presente e disposto a compartilhar a experiência de dançar junto. E coloca que, ao criar essa atmosfera de harmonia e unidade, todos têm a possibilidade de se conectar consigo mesmos e com os demais praticantes que compõem a roda. Elucido aqui também, as palavras de uma participante da primeira ação, que ratificam a afirmativa de Camargo: "as pessoas que estavam do meu lado, me ajudaram e isso fez toda a diferença".

Perazzolo et. al. (2013) tonificam e corroboram dizendo que, para que uma relação se estabeleça, é necessário que, pelo menos, dois sujeitos (ou grupos) estabeleçam uma interlocução da qual se origine um espaço 'entre' um e outro. Só assim, o estar 'entre', irá proporcionar a troca relacional, deixando ao sujeito que dança, a sensação de bem-estar e liberdade de expressão. Pode-se perceber, que essa assertiva está ligada ao sinalizador da hospitalidade quando, uma participante, da terceira ação investigativa, atesta em sua fala: "Essa sensação de estar no meio de pessoas que você não conhece e mesmo assim se sentir bem é algo fora do comum”.

Similarmente a estas afirmações, Morin (2005) expõe que na construção intelectual, o ser humano constitui-se sempre a partir do 'outro', constrói e se reinventa nunca sozinho, mas, em grupo, em sociedade. Sendo preciso conhecer-se e reconhecer-se, a fim de conseguir entender o 'outro'.

Desta forma, a dança circular permeia essa construção e reconstrução do intelectual do ser humano, pois, as inter-relações que são vivenciadas na roda, fazem pensar, repensar e, quem sabe, modificar ações de si e frente ao 'outro'. Assim, as relações provocarão no sujeito que dança, a experiência corporal que irá traduzir em movimentos a expressividade, também, informações e conhecimento que serão aprendidos e apreendidos, fazendo refletir e perceber mudanças internas sendo exteriorizadas. Com isso, Jayme e Fausto (2011) apud Reis et. al (2017), expõem que, pôde-se observar que o desenvolvimento da dança circular efetuada com o 
ÁVILA, Newton e BAPTISTA, Maria Luiza Cardinale. A

propósito de modificar relações do sujeito que dança, trouxe como benefícios o equilíbrio dos corpos físico, emocional, mental e espiritual. Favoreceu a ampliação da percepção, do autoconhecimento, do respeito, da inclusão e do apoio mútuo entre os participantes. Propiciou uma melhor consciência corporal, concentração, atenção, ritmo e referência espacial. Oportunizou o fortalecimento da autoestima. E ainda, possibilitou a alegria e a paz interior de cada pessoa.

Conjuntamente, não tem como pensar em relações, sem atribuir esse pensamento ao acolhimento e à amorosidade, possibilitando constituir vínculos que serão expressados no convívio de quem dança. $\mathrm{O}$ acolhimento, traz consigo o reconhecimento do outro na convivência, mudando a forma de se relacionar. Acolher é então, se envolver, trocar e entrelaçar. Complementam ainda essa reflexão, Camargo (2004), Boff (2005) e Avena (2006) citados por Santos e Baptista (2014), ao expor que entendem que a definição de acolhimento, com ênfase na relação, se constitui para além do fato social, considera dimensões do cuidado e pressupõe o reconhecimento do acolhido, este concebido como origem para a definição das ações de hospitalidade. Essas constatações vêm ao encontro da dança circular, que pressupõe a relação 'eu' e o 'outro', por meio do círculo e do auxílio mútuo entre os sujeitos. Na roda, segundo Camargo (2015), todos são bem-vindos, não importando a idade, a estética corporal, a classe social, a situação econômica, a posição política e a atividade profissional de cada pessoa. Cito, duas falas trazidas por dois participantes, da terceira e da quarta ação investigativa, que resumem as afirmações acima: "dançar em círculo na roda é poder olhar e ver todo mundo, olho no olho, sabe, e sentir que você não está sozinho". "Dançar de mãos dadas faz com que a gente perceba que o outro existe e preste atenção nele”.

Em igual intensidade, a amorosidade, uma característica que garante amor e acolhimento para tornar as relações mais agradáveis é introduzida naturalmente no sujeito que dança. Pois, a amorosidade liberta e é uma atitude que começa na mente e acaba se instalando no coração, como um jeito novo de ser, e só acontece em quem é capaz de amar. Ao discorrer sobre as emoções, Maturana (1998) traz afirmações de que o resultado disto é que, o viver humano se dá num contínuo entrelaçamento de emoções e linguagem como um fluir de coordenações consensuais de ações e emoções. O amor, trazido por Maturana (1988), é a emoção que constitui as ações de aceitar o "[...] outro como um legítimo outro na convivência [...]" (MATURANA, 1998, p. 25). 
Portanto, amar é abrir um espaço de interações recorrentes com o 'outro', no qual sua presença é legítima, sem exigências. Com isso, a ação da amorosidade, também permite, que se aproximem as pessoas do conjunto de virtudes, pois, nela estão incluídos o cuidado, o respeito, a confiança e estabeleçam laços sociais no convívio. E é o que se pôde perceber no desenvolvimento da dança circular com os integrantes, imbuídos na roda, de mãos dadas, envoltos por um sentimento pleno e puro. "No momento desse contato temos a união de espírito e matéria e a possibilidade da criação. O ser humano se torna um ser íntegro quando se torna criativo. A partir daí ele tem a trindade dentro de si [...]” (RAMOS, 1998, p.3). Complementa esse pensamento, a declaração de uma participante da quinta ação investigativa, que diz: "A dança me faz bem, sempre que posso participo de um grupo de danças circulares, isso me fortalece. Dá uma sensação que não sei explicar. Um bem-estar que fica o dia inteiro. Foi o que senti aqui”.

Ao referir-se em laços sociais, e nela buscar suas tonalizações de positividade, é pertinente trazer novamente o que diz Santos $(2014$, p. 13) que, “[...] remete à ideia de amarras cuja tessitura se faz em relações genuínas de acolhimento [...]”. É, também, compreensível dizer que fortalecem vínculos, e qualificam as vivências dos sujeitos na cotidianidade. Assim, nas palavras de Santos, ao se reconhecer, interagir e se hospedar mutuamente, os sujeitos se transformam alternadamente no outro, e, consequentemente, direcionam o olhar para o olhar do 'outro'.

Com tal característica, pode-se dizer que há um entrecruzamento entre o acolhimento e a amorosidade na dança circular, pois, o acolhimento é abrir o espaço próprio sem reservas ou desconfianças (BAPTISTA, 2008) e a dança circular produz e se alimenta da amorosidade. Dessa forma, o sujeito ao participar da dança, exclui pré-conceitos e vivencia o pertencimento ao grupo, recebendo e dando de si a energia da composição do círculo com as mãos dadas, exprimindo suas emoções. As vivências podem trazer ao sujeito uma significativa estruturação nas relações, baseando sua conjectura no sentir, relacionar-se e tocar. A dança traz consigo o tato, o contato com o toque das mãos. E, reforçando o que já foi dito, o toque permite uma mistura que envolve uma movimentação de energias, de intensidades e de afetos (ROLNIK, 1989).

Cabe reforçar a importância do toque trazido por Rolnik, em que o acolhimento e a amorosidade se entrecruzam na dança circular, assim, faz-se importante citar uma manifestação 
ÁVILA, Newton e BAPTISTA, Maria Luiza Cardinale. A

oral. Trata-se da fala de uma participante da primeira ação investigativa: "Eu quando era pequena minha mãe contava histórias pra dormir, a gente fazia boneca com sabugo de milho, porque nós não tinha dinheiro e tinha que trabalhar na roça, e às vezes, de tardinha, a gente dançava de mãos dadas. Minha mãe era muito alegre. Eu fui casada duas vezes. Meu primeiro marido era seco, meio grosso, não gostava dessas coisas. Mesmo assim, eu brincava de roda com meus filhos".

Ao trazer essas reflexões, o que pode ser considerado nas relações para oferecer sinalizadores para a hospitalidade, são que, a configuração da hospitalidade, além das questões estruturais do fenômeno de estudo, está centrada no ato do bem receber e ser bem recebido. O acolhimento é o reconhecimento do outro na convivência. Ao acolher há o envolvimento, a troca e o entrelaçamento. A amorosidade, é deixar despertar em seu interior a plenitude do amor. Um amor sem rótulos, que não tenha pré-conceitos e não apresente distinções.

E, por fim, a dança circular, na sua composição da roda, de mãos dadas e pelas amarrações circulares, consegue-se exprimir movimentação, sensações, sentimentos e emoções, podendo constituir percepções, vínculos e relações. O toque é a autorização para a entrada do 'outro' no próprio espaço. É fator determinante para consolidar o olhar do 'outro', despindo-se de qualquer julgamento. Neste âmbito, a percepção tátil se abre para o descortinar-se perante o 'outro'. Pois, ao tocar e ser tocado na dança circular, há a inserção da permissão de envolvimento, fluidez necessária para a constituição das emoções, do acolhimento e da amorosidade, que por sua vez, terá resultados diferenciados na comunicação, no expressar-se.

Com tais amarrações tecidas, ao analisar a dança circular nas práticas das ações investigativas e, em outros momentos de experimentação do dançar em roda, feitos pela minha trajetória de vida, é possível perceber que, a dança circular exerce uma função importante na conjuntura das relações. Oferece o desprendimento e a libertação dos sujeitos para se reconhecer e entender o 'outro'. Concebe em sua ação, uma prática de bem-estar e desenvolvimento pessoal. Também, nas vivências propiciadas pelos sujeitos que dançam e suas expressividades corporais evidenciadas ao finalizar a dança, pode-se dizer que, a dança circular faz bem ao corpo, às emoções, à mente e ao espírito. Esses, são, reforçando, em suma, alguns dos itens que compõem as vantagens trazidas pela execução da dança circular.

Pode-se pensar a partir disso que, para que as relações tenham maior intensidade causando a proximidade e estendendo os laços sociais, é preciso que haja a reciprocidade e 
aceitação mútua por parte de cada pessoa. Neste contexto, torna-se importante ainda, que deve haver um fundamental alinhamento entre o estar disposto a aceitar o "[...] outro como legítimo outro na convivência [...]" (MATURANA, 1998, p. 25) e introduzir o conviver - com tato - nas relações. Pois só assim, as mudanças acontecerão, ocorrendo uma modificação na expressividade das emoções, gerando novo comportamento, a conservação da nova rede de conversações para assegurar e constituir a nova cultura (MATURANA; VARELA, 2011). E buscar internamente a consciência percepção/corporal que trará a transformação espontânea na história do conviver, utilizando-se do toque no dançar em roda para fortalecer os sentimentos exteriorizados pelos sujeitos.

É tudo uma questão de olhar. Entender e interpretar. Assim, para finalizar, Berger (1999, p.10) diz que o "[...] olhar é um ato de escolha. Como resultado dessa escolha, aquilo que vemos é trazido para o âmbito do nosso alcance - ainda que não necessariamente ao alcance da mão. Tocar alguma coisa é situar-se em relação a ela [...]”.

\section{CONSIDERAÇÕES TEMPORÁRIAS}

Este estudo conduziu, por meio da estratégia metodológica Cartografia de Saberes, um modo de conhecer, de fazer pesquisa, produzindo instrumentos de proximidade entre a teoria e o campo. Na parte do campo, executando a dança circular, em diversos ambientes, possibilitou a contiguidade com as pessoas, suas histórias de vida - absorvidas nos relatos -, o contato com tato, perfazendo, através do toque, a troca relacional. Por isso, foi nítido observar as expressões de corpos que traduziam soltura, bem-estar, acolhimento e amorosidade, no dançar em roda. Foi criada uma comunicação baseada na busca do consenso (aceitação e troca), tendo sido possível perceber o estabelecimento de laços de proximidade nas relações. Há que ser salientado que essas constatações foram em cima das ações práticas desenvolvidas não sendo uma verdade absoluta para todas as execuções de dança circular, o que permite diversas reações dos participantes e pode falsear ou confirmar as averiguações.

A apresentação das danças circulares como um todo, recupera e integra antigas formas de expressões de diferentes povos. Acrescida de novas criações, coreografias e ritmos, que, através da consciência de um centro comum, auxilia no desenvolvimento de capacidades como consciência corporal, ritmo, lateralidade, capacidade cardiovascular, cooperação, sociabilização, dentre outros. Também favorece a integração, busca de autoconhecimento 
individual e grupal como a modificação gradativa das relações. Permite a arte do encontro, no círculo, unidos pelo toque das mãos, em que se produz a cooperação e ajuda mútua, simplesmente por fazer a roda se movimentar harmonicamente. É justificável afirmar, neste contexto, a importância da dança e os seus reflexos na vida cotidiana. Em qualquer situação, é possível de perceber uma sensação rítmica, através da sucessão das movimentações dançantes, que transmitem sentimentos de libertação emocional.

Em síntese, retomando os objetivos, o presente trabalho trouxe como respostas que basta transformar a maneira particular de observar, em percepções que comunicam, que expressam sentido, que dão veracidade aos fatos, tornando-os reais aos acontecimentos e no interior de cada pessoa. Então, é possível afirmar que os objetivos do trabalho foram atingidos, quando se apresentou a dança circular num contexto relacional entre os sujeitos e pôde-se perceber que os participantes da roda se sentiram à vontade, se despiram de preconceitos, vivenciando e experimentando o novo, o desconhecido. Igualmente, quando se relacionou os conceitos de acolhimento e amorosidade à dança circular, propondo entender que o acolhimento traz consigo o reconhecimento do 'outro' na convivência. Envolvendo-se. Trocando experiências. Entrelaçando sentimentos e emoções por meio do toque, com base na afetividade expressada pela amorosidade na dança. E, no terceiro objetivo, quando se identificou sinalizadores de hospitalidade, nos vínculos marcados pelo acolhimento e amorosidade, em decorrência da prática com as ações investigativas da dança circular. Nesse sentido, emergiram alguns sinalizadores para a hospitalidade.

No desenvolvimento da pesquisa, pôde-se perceber a dança circular como expressão de vínculos de acolhimento e amorosidade. Assim, tem-se, por meio dela, uma forma de integrar o corpo e sua expressividade. Trata-se, portanto, de uma situação de comunicação e expressão. Embasando a comunicação do sujeito com o 'outro', é capaz de acionar o pensamento e explorar a criatividade, para improvisar e, ao mesmo tempo, estabelecer a conexão de troca com este 'outro', o desconhecido.

À vista disso, vivenciar a dança circular, por meio da prática cooperativa, é desfrutar de uma nova-velha forma de lidar com as relações humanas em equipes de trabalho e em nossas próprias vidas, certamente como faziam nossos ancestrais.

A dança circular é uma forma de envolvimento de amorosidade e acolhimento. Desse modo, ao estar de mãos dadas em uma roda, cada pessoa vivencia a sensação de pertencimento. 
Cada um é parte de algo maior que eles mesmos e que existe apenas porque cada um está onde está.

Nessa perspectiva, a dança circular parece permear a expressividade (emoções e sentimentos), provocar soltura nos corpos, relaxar e criar relação-convívio. Assim, ao participar do círculo, o sujeito amplia o conhecimento em direção ao bem-estar físico, mental, emocional, energético e social e pode ser vista como processo educativo que costura as relações interpessoais.

Ao exprimir o conjunto de reflexões sobre as relações na dança exposta neste texto, pode-se dizer que é admissível perceber, na dança circular, uma função importante na conjuntura das relações, por proporcionar, a sua ação, numa prática de bem-estar e desenvolvimento pessoal.

À vista disso, imbuído por inquietações ao iniciar o estudo, deixei-me conduzir, na construção teórica, pela leitura de textos, artigos, livros, e, somadas às ações práticas, por meio das aproximações e ações investigativas com vivências e relatos, estruturei o suporte necessário à escrita deste texto. Foram movimentos, ações, gestos, expressões, sorrisos, olhares, abraços, que se misturaram às emoções e ajudaram a elaborar a palavra escrita. Assim, com a intensa etapa de tempo vivido, pronunciadas pelas experiências e sensações, pude constatar que realizar a pesquisa desencadeou ampliar conhecimentos, criar vínculos, aprender e apreender histórias de vida, reformular pensamentos e modificar direções na caminhada do cotidiano. Do mesmo modo, pude acolher e ser acolhido.

Dessa forma, reconheço que o que apresento é uma espécie de dança circular de saberes, apreendida entre os colegas e professores do programa - nas aulas, com vivências, observações, participações -, e, também, por meio de pessoas que participaram das atividades em outras situações. Argumento que, "o corpo dança. Faz contato. Toca. E tem no toque a autorização para a entrada do 'outro' no próprio espaço. Vivencia. Experimenta. Aprende. Ensina. Apreende. Modifica modos de viver e interagir. Ao dançar, se redescobre. Fica à vontade. Se envolve. Se entrelaça. Acolhe. Ama”.

\section{REFERÊNCIAS}

AVENA, Biagio Mauricio. Por uma pedagogia da viagem, do turismo e do acolhimento: itinerários pelos significados e contribuições das viagens à (trans)formação de si / Biagio 
Mauricio Avena. Tese (doutorado) - Universidade Federal da Bahia. Faculdade de Educação, 2008. 516 p. Disponível em: https://repositorio.ufba.br/ri/bitstream/ri/11806/1/Tese\%20Biagio\%20Avena.pdf Acesso em: agosto/2017.

BAPTISTA, Isabel. Hospitalidade e eleição intersubjetiva: sobre o espírito que guarda os lugares. Revista Hospitalidade, v. 5, n. 2, p. 5-14, 10 dez. 2008. Disponível em: https://www.revhosp.org/hospitalidade/article/view/150 Acesso em: dezembro/2016.

BAPTISTA, Isabel. Para uma geografia de proximidade humana. Revista Hospitalidade, São Paulo, ano 2, n. 2, p. 11-22, 2. sem. 2005. Disponível em: https://www.revhosp.org/hospitalidade/article/view/219 Acesso em: dezembro/2016.

BAPTISTA, Maria Luiza Cardinale. Cartografia de Saberes na pesquisa em Turismo: Proposições Metodológicas para uma Ciência em Mutação. Revista Rosa dos Ventos Turismo e Hospitalidade, 6(3) 342-355, jul-set, 2014. Disponível em: http://www.ucs.br/etc/revistas/index.php/rosadosventos/article/view/2647 Acesso em: janeiro/2017.

BAPTISTA, Maria Luiza Cardinale. Caosmose, desterritorialização e amorosidade na comunicação. Questões Transversais - Revista de Epistemologias da Comunicação. Vol. 2, no 4, julho-dezembro/2014. Disponível em: http://revistas.unisinos.br/index.php/questoes/article/view/9625/PDF Acesso em: junho/2017.

BERGER, John. Modos de ver. Rio de Janeiro: Rocco, 1999. 168 p.

CAMARGO, Giselle Guilhon Antunes (Org.). Antropologia da dança II. Florianópolis: Insular, 2015. 304 p.

CAMARGO, Luiz Octávio de Lima. Os interstícios da Hospitalidade. Revista Hospitalidade. São Paulo, v. XII, n. especial, p. 42-69, mai. 2015. Disponível em: https://www.revhosp.org/hospitalidade/article/view/574 Acesso em: dezembro/2016.

COSTA, A.L. B. da. Danças: uma herança à disposição de Todos. In: RAMOS, R. L. C. (Org). Danças Circulares: uma proposta de educação e de cura. São Paulo: Triom. 1998. 194 p.

COUTO, Yara Aparecida. Dança Circular Sagrada e seu Potencial Educativo. Tese (Doutorado). Faculdade de Ciências Humanas, Programa de Pós-Graduação em Educação, Piracicaba, SP, 2008. Disponível em: https://www.unimep.br/phpg/bibdig/pdfs/2006/NTFYKKWCNQAQ.pdf Acesso em: novembro/2016.

FARO, Antônio José. Pequena história da dança. $7^{\text {a }}$ edição. Rio de Janeiro: Jorge Zahar, 2011. 150 p. 
ÁVILA, Newton e BAPTISTA, Maria Luiza Cardinale. A

FOUCAULT, Michel (1999). A arqueologia do saber. 7.ed. Rio de Janeiro: Forense Universitária, 2004. 236 p.

FREIRE, Paulo. A Educação na Cidade. São Paulo: Cortez Editora, 1991. 144 p.

GIL, A. C. Métodos e técnicas de pesquisa social. 5.ed. São Paulo: Atlas, 1999. 207 p.

LÉVINAS, Emmanuel. Totalidade e infinito. Lisboa, Portugal: Edições 70, 1988. 287 p.

MATURANA, Humberto R. Emoções e linguagem na educação e política. Belo Horizonte: UFMG, 1998. 103 p.

MATURANA, Humberto R.; VARELA, Francisco J. A árvore do conhecimento: as bases biológicas da compreensão humana. 9. ed. São Paulo: Palas Athena, 2011. 283 p.

MERLEAU-PONTY, Maurice. Fenomenologia da percepção. Trad. Carlos Alberto Ribeiro de Moura. São Paulo: Martins Fontes, 1994. (Texto original publicado em 1945). 465 p.

MORIN, Edgar. A cabeça bem-feita: repensar a reforma, reformar o pensamento. 20. ed. Rio de Janeiro: Bertrand Brasil, 2012. 128 p.

MORIN, Edgar. Ciência com consciência. 9. ed. Rio de Janeiro: Bertrand Brasil, 2005. 344 p.

MORIN, Edgar. Os sete saberes necessários à educação do futuro. 9. ed. São Paulo: Cortez, 2004. 118 p.

OSTETTO, L.E. Educadores na roda de dança: formação-transformação. 2006. 250 p. Tese (Doutorado em Educação) - Programa de Pós-Graduação em Educação, Universidade Estadual de Campinas, Campinas/SP. Disponível em: https://repositorio.ufsc.br/xmlui/handle/123456789/88883 Acesso em: dezembro/2016.

PERAZZOLO, O.; SANTOS, M. M. C.; PEREIRA, S. Dimensión relacional de la acogida. Estudios y Perspectivas en Turismo. Centro de Investigaciones y Estudios Turísticos, Buenos Aires, Argentina, 2013. Disponível em: http://www.redalyc.org/articulo.oa?id=180725735008 Acesso em: maio/2017.

POWELL, T.G.E. Os celtas. Lisboa: Verbo, 1965. 282 p.

RAMOS, R. L. C. (Org). Danças Circulares: uma proposta de educação e de cura. São Paulo: Triom. 1998. 194 p.

REIS, Marcelle Santos dos; TIBEAU, Cynthia Cleusa Pasqua Mayer; MUTARELLI, Maria Cristina; NETO, Maria Inês Artaxo. Proposta de inclusão das danças circulares nas aulas de ginástica laboral. Revista Multidisciplinar do Nordeste Mineiro - ISSN 2178-6925. Faculdade Presidente Antônio Carlos de Teófilo Otoni - Junho de 2017. (Págs. 353 a 365). In: JAYME, D.; FAUSTO, E. Danças Circulares. Projeto Cooperação. 2011. 
Disponível em: http://www.unipacto.com.br/revista2/arquivos_pdf_revista2017/24.pdf Acesso em novembro/2017.

ROLNIK, Suely. Cartografia sentimental: transformações contemporâneas do desejo. São Paulo: Estação Liberdade, 1989. 304 p.

ROMAGNOLI, Roberta Carvalho. A cartografia e a relação pesquisa e vida. Psicol. Soc. [online]. 2009, vol.21, n.2, pp.166-173. ISSN 0102-7182. http://dx.doi.org/10.1590/S010271822009000200003. Disponível em: http://www.scielo.br/pdf/psoc/v21n2/v21n2a03.pdf

Acesso em: abril/2017.

RUDIO, Franz Victor. Introdução ao projeto de pesquisa cientifica. 30. ed. Petrópolis: Vozes, 2002. 144 p.

SANTOS, Marcia Maria Cappellano dos. A metáfora laços sociais e a hospitalidade (p. 13 a 17). In: Laços Sociais: por uma epistemologia da hospitalidade. SANTOS, Marcia Maria Cappellano dos; BAPTISTA, Isabel (Org.). Caxias do Sul, RS: EDUCS, 2014. 280 p.

SANTOS, Marcia Maria Cappellano dos; BAPTISTA, Isabel (Org.). Laços sociais: por uma epistemologia da hospitalidade. Caxias do Sul, RS: EDUCS, 2014. 280 p.

SESC. Serviço Social do Comércio. (www.sesc.com.br). 2017.

WOSIEN, Bernhard. Dança: um caminho para a totalidade. São Paulo: TRIOM, 2000. 157 p.

Artigo recebido em: 07/04/2018

Avaliado em: 23/06/2018

Aprovado em: 28/06/2018 